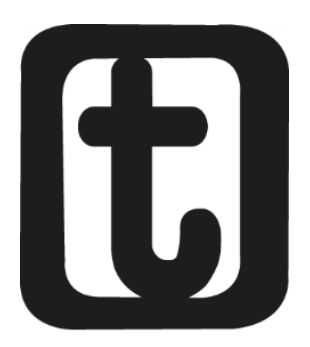

\title{
O PROJETO DA MODERNIDADE, CRISE CAPITALISTA E IDEOLOGIA PÓS-MODERNA
}

The project of modernity, capitalist crisis and post-modern ideology

\section{Danielle Viana Lugo Pereira' Altair Reis de Jesus ${ }^{2}$}

\section{RESUMO}

A presente comunicação parte de autores como Habermas, Berman, Harvey e Bauman para evidenciar o significado, bem como, as controvérsias presentes no projeto da modernidade e sua negação pelo discurso pós-moderno. Neste sentido, buscamos uma reflexão teórica sobre o rumo tomado pelo capital e seus reflexos na atualidade. Sobretudo ao que diz respeito à lógica de produção e circulação capitalista, ou seja, o impasse na sobrevivência da humanidade, subordinada às leis da mercadoria e à destruição em massas de forças produtivas que se sucede a cada crise econômica, ofuscados em grande medida em função de fatos de ordem conjuntural.

\footnotetext{
${ }^{1}$ Assistente Social, Mestre em Serviço Social e Especialista em Direitos Humanos pela UFPB, Professora do Curso de Graduação de Serviço Social da Universidade Federal da Bahia. E-mail: <daniellelugo.ufba@gmail.com>.

${ }^{2}$ Sociólogo, Doutorando em Ciências Sociais (UFBA). Mestre em Ciências Sociais (UFBA). E-mail: <altairreis2006@hotmail.com >.
} 


\section{temporolis}

PEREIRA, D. V. L.; JESUS, A. R. de. O PROJETO DA MODERNIDADE

\section{PALAVRAS-CHAVE}

Modernidade. Capitalismo. Estado. Razão. Ideologia.

\section{ABSTRACT}

This communication from authors such as Habermas, Berman, Harvey and Baumanto highlight the significance and the controversy present in the project of modernity and its denial by the postmodern discourse. In this sense, we seek a theoretical reflection on the path taken by capital and its consequences today. Particularly with respect to the logic of capitalist production and circulation, the deadlock on the survival of humanity, subject to the laws of the goods and the mass destruction of productive forces that ensues every economic downturn, largely overshadowed in the light cyclical order of events.

\section{KEYWORDS}

Modernity. Capitalism. State. Reason. Ideology.

Submetido em 30/04/2011

Aceito em 10/06/2011

\section{A MODERNIDADE NAS CONCEPÇÕES DE HABERMAS, BERMAN E HARVEY}

A modernidade remete-nos ao seu conceito filosófico tendo em vista caracterizar e situar a materialidade do tempo e do espaço na vida presente posta em desafios que não estão desassociados do passado histórico. Autores como Habermas (2002; 1975), Berman (1982) e Harvey (1992) nos fornecem alguns elementos explicativos para entendermos como se configuraria o projeto advindo da modernidade, bem como, suas implicações econômicas, políticas, sociais e culturais presente no capitalismo e sua fase tardia. Deste modo, a reflexão inicial sobre a modernidade tem no discurso de Habermas (2002; 1975) um delineamento abrangente sobre os rumos adotados pela humanidade pautada no projeto da razão. Retomando aspectos centrais do pensamento weberiano acerca 


\section{tempordils}

PEREIRA, D. V. L.; JESUS, A. R. de. O PROJETO DA MODERNIDADE

da modernidade Habermas (2002; 1975) aponta para o processo de racionalização da vida atual em contraposição ao que se considerava como tradicional. Este processo permitiu que a humanidade desse um salto magnífico rumo ao desenvolvimento das suas capacidades produtivas, culturais e sociais patrocinadas e regulamentadas pelos Estados Nacionais e pela burguesia industrial.

Sobre o conceito de modernização é pertinente a afirmação do autor acerca de como se define o projeto da modernidade.

O conceito de modernização refere-se a um conjunto de processos cumulativos e de reforço mútuo: á formação de capital e mobilização de recursos; ao desenvolvimento das forças produtivas e ao aumento da produtividade do trabalho; ao estabelecimento do poder político centralizado e a formação de identidades nacionais; a expansão dos direitos de participação política, das formas urbanas de vida e da formação escolar formal; à secularização dos valores e normas, etc (HABERMAS, 2002, p. 5).

O processo de modernização abarcou todas as esferas do desenvolvimento humano passando pela construção dos Estados Nacionais, da classe burguesa, da formação do proletariado, da acumulação capitalista que na atualidade alcançou níveis elevados - via mercados financeiros - gerando crises cada vez mais profundas que colocariam em risco o próprio futuro da humanidade. Sobre as consequências advindas do desenvolvimento capitalista e suas sucessivas crises a ideologia burguesa $^{3}$ busca justificá-las por intermédio de discursos

\footnotetext{
3 Entenda aqui ideologia burguesa (grifo nosso) como uma falsa consciência no sentido posto por Marx (1999) presente na Ideologia Alemã, obra escrita em parceria com Friedrich Engels entre 1845-1846.
} 


\section{temporolis}

PEREIRA, D. V. L.; JESUS, A. R. de. O PROJETO DA MODERNIDADE

enviesados da economia política e, sobretudo, por um discurso ideológico de perspectiva pós-moderna que considera os processos históricos não mais como um projeto fruto do desenvolvimento da humanidade centrado na razão/esclarecimento, mas sim, fragmentado e desprovido de projeto político totalizador das demandas sociais vivenciadas pelo conjunto da sociedade.

Além disso, vale salientar que o conceito de modernidade foi primeiramente definido de forma bastante clara por Hegel (2008). Para Habermas (2002) seria necessário retomar as premissas hegelianas sobre a modernidade para entendermos o que significou a relação interna entre a modernidade e a racionalidade e sua importância para o advento do esclarecimento como porta de saída do mundo dos mitos e tradições no qual se estabelecia as culturas antigas e medievais.

Hegel emprega o conceito de modernidade, antes de tudo, em contextos históricos, como conceitos de época: 'os novos tempos" são os tempos modernos'. Isso corresponde ao uso contemporâneo do termo em inglês e francês: por volta de 1800, modern times e temps modernes designam os três séculos precedentes. A descoberta do 'Novo Mundo' assim como o Renascimento e a Reforma, os três grandes acontecimentos por volta de 1500, constituem o limiar histórico entre a época moderna e a medieval (HABERMAS, 2002, p. 9).

A modernidade - tempos modernos - não deseja tomar como parâmetro modelos de outras épocas uma vez que seus critérios de orientação são retirados de si mesma. Dito desta forma a modernidade se vê referenciada em si mesma, sem apelar a subterfúgios e questionando o sentido de imitação de modelos antigos, sobretudo ao suplantar uma concepção de beleza baseada 


\section{temporalis}

PEREIRA, D. V. L.; JESUS, A. R. de. O PROJETO DA MODERNIDADE

na ordem absoluta e supratemporal em relação a critérios do belo relativo ou condicionado temporalmente articulado com autocompreensão do lluminismo francês e de um novo começo de época. Neste aspecto a modernidade ou o projeto moderno pode se concebido como uma época histórica no instante que toma consciência da ruptura feita com o passado, assim como, da necessidade de extrair tudo que é normativo, enquanto problema histórico. Neste contexto a modernidade apresenta-se como o período em que a humanidade expandiu todas as suas possibilidades de desenvolvimento no que concerne a sua capacidade criativa e transformadora da natureza. Este elemento nos parece central já que neste movimento em busca do progresso material e cultural da humanidade a natureza foi subjugada ao domínio da ciência e da técnica ${ }^{4}$ sob a lógica do capital cujos resultados colocam em risco o próprio destino do planeta. Contudo o projeto moderno significou também mudanças profundas no tempo e no espaço patrocinados pela industrialização e expansão dos meios de transporte e comunicação, salientados também por Berman (1982) e Harvey (1992).

Sendo assim, conforme Berman (1982) a partir das concepções marxistas, fundamentalmente, do pensamento de Marx, nos diz que a modernidade significa que "[...] todas as relações sociais tornam-se obsoletas antes mesmo que se ossifiquem, isto é, tudo que é sólido desmancha no ar [...]" (MARX apud BERMAN, 1982, p, 20). Para Berman (1982) o que está posto é a radicalização da modernidade em que autores como Marx e Nietzsche, apenas contemplaram em partes seu projeto inacabado, haja vista que nos seus contextos históricos primordiais a modernidade - sob a lógica

\footnotetext{
4 Segundo Habermas (1975) a dominação da natureza pelo homem na sociedade capitalista por intermédio da ciência e da técnica tenderia a produzir efeitos fatais para o conjunto da sociedade.
}

Temporalis, Brasilia (DF), ano 10, n.20, p.31-47, jul./dez. 2010. 


\section{tempordils}

PEREIRA, D. V. L.; JESUS, A. R. de. O PROJETO DA MODERNIDADE

do capital - estava circunscrita, essencialmente, na Europa. Essa radicalização da Modernidade e suas múltiplas formas foram se espalhando ao longo dos séculos pelo resto do mundo. O autor identifica três fases, a saber: a primeira surgida no curso do século XVI e até meados do século XVIII (em que as pessoas estavam num estado de semicegueira); a segunda, emergida pelas Grandes Revoluções do século XIX em que as pessoas estavam atordoadas pela ambiguidade entre dois mundos completamente diferentes, um atrelado às idéias das tradições e um outro desmistificando essas idéias através de pressupostos científicos a serviço da supremacia da razão.

A modernidade está intrinsecamente ligada ao advento do capitalismo e suas formas destrutivas uma vez que nada e nem ninguém permanece longe das consequências da corrida dos capitalistas em busca de valorizar valor, através da extração da mais-valia da classe trabalhadora. Deste modo, o elemento central da modernidade está posto pela relação contraditória da compra e venda da mercadoria força de trabalho, isto é, o antagonismo de classe social entre os detentores dos meios de produção e os que, apenas, detém sua força de trabalho. Resulta, daí, um dos paradoxos fundamentais da modernidade, qual seja, a riqueza cada vez mais construída socialmente pela divisão social do trabalho em sua fase global, porém o acesso aos bens socialmente produzidos concentra-se ainda mais nas mãos de uma pequena burguesia. Portanto, na medida em que a classe trabalhadora produz riqueza para os capitalistas gera também sua própria pobreza, isto é, a riqueza socialmente produzida em larga escala constitui no empobrecimento daqueles que a produz.

De um lado, tiveram acesso à vida forças industriais e científicas de que nenhuma época anterior, na história da humanidade, chegara a suspeitar. De outro lado, 


\section{temporalis}

PEREIRA, D. V. L.; JESUS, A. R. de. O PROJETO DA MODERNIDADE

estamos diante de sintomas de decadência que ultrapassa em muito os horrores dos últimos tempos do Império Romano. Em nossos dias, tudo parece estar impregnado do seu contrário. [...] o homem parece escravizar-se a outros homens ou à sua própria infâmia. [...] (MARX apud BERMAN, 1982, p. 19).

Nesse sentido, temos visto essa duplicidade paradoxal porque se diariamente vivemos num mundo expresso pela produção de riqueza (in)material e do conhecimento antes nunca pensados pelos povos antigos. Ao mesmo tempo, vivemos num mundo regido pela égide do capital, que de acordo com Marx (2001) tem um caráter intrínseco de autodestruição inovadora, tudo que é construído tem como finalidade sua própria destruição, tudo é feito para ser colocado no chão (MARX, 2001, p. 48). Segundo Berman (1982, p. 98) a classe burguesa vem sendo a mais violenta destruidora de toda a história. Posto isto, captamos da leitura de Berman (1982) que o significado da modernidade é, sobretudo, o próprio capital em movimento trazendo consigo as mais terríveis contradições nunca antes vistas.

Para Harvey (1992) seria fundamental decifrar o movimento do capital num mundo cada vez mais redesenhado pela compreensão de tempo e do espaço, tendo em vista que de acordo com o mesmo a terra em tempos de modernidade foi significativamente diminuída, exemplo disso foi o que aconteceu com a nossa capacidade de se locomover. Vejamos o exemplo bastante elucidativo que Harvey (1992) aponta, a saber: entre os séculos XVI e XVIII os principais meios de transportes constituíam, basicamente, de carruagens e de barcos a vela com capacidade, aproximadamente, de $16 \mathrm{~km} / \mathrm{h}$. Com o advento da radicalização da modernidade chegamos à marca de $1.100 \mathrm{~km} / \mathrm{h}$. Portanto, para Harvey (1992) o espaço e o tempo são categorias básicas da existência humana. Com isso, qual seria a relevância de 


\section{tempordils}

PEREIRA, D. V. L.; JESUS, A. R. de. O PROJETO DA MODERNIDADE

compreender a modernidade considerando o ritmo do tempo e a localização espacial? Quais seriam as consequências de um reordenamento da dinâmica da vida a partir da aceleração, em especial, posta no processo de produção e reprodução das relações sociais? Como resposta as indagações Harvey (1992) cita algumas descobertas que contribuíram para a expansão do capitalismo a níveis globais, por exemplo, o cronômetro, calendário e mapas os quais contribuíram para (re) significar a vida em sociedade. Além disso, fundamentalmente, essas descobertas foram utilizadas racionalmente para atender a lógica da acumulação capitalista. O calendário e a medida do tempo foram apropriados pela burguesia como recurso de organizar e disciplinar a força de trabalho. De acordo com Harvey (1992, p.209-210) “[... ] o mapeamento do mundo abriu caminho para que se considerasse o espaço algo disponível à apropriação para usos privados". Portanto, "[...] a troca de mercadorias materiais envolve a mudança de localização e o movimento espacial”. Em suma, “[...] quando mais rápida a recuperação do capital posto em circulação, tanto mais o lucro obtido".

Deste modo, “[...] é nesse contexto que a adaptabilidade e flexibilidade dos trabalhadores se tornam vitais para o desenvolvimento capitalista". Exemplo contemporâneo disso é o que ocorre com os trabalhadores da área de telemarketing que em média tem que a cada ligação assinar contrato considerando o tempo de 28 segundos (HARVEY, 1992, p.211). Assim, as transformações ocorridas pela compreensão de espaço e do tempo, ao longo da chamada modernidade, são absorvidas pelas dimensões sincrônicas e diacrônicas do desenvolvimento capitalista. Nessa perspectiva, Harvey (1992, p.257) questiona “[...] como os usos significativos do espaço e do tempo mudaram com a transição do fordismo para acumulação flexível?". Para responder essa indagação tomamos por base alguns aspectos sugeridos pelo 


\section{temporalis}

PEREIRA, D. V. L.; JESUS, A. R. de. O PROJETO DA MODERNIDADE

autor: a) A crise aberta em 1973; que acarretou na mudança do padrão de acumulação, da rigidez promovida pelo fordismo ao padrão advindo da flexibilidade do toyotismo, considerando a exacerbação do sistema do jus-in-time; b) A aceleração do tempo de giro na produção envolve acelerações paralelas na troca e no consumo; c) "Os bancos eletrônicos e o dinheiro de plástico foram algumas inovações que aumentaram a rapidez do fluxo de dinheiro inverso"; d) Tendência da passagem do consumo de bens para o consumo de serviços; e) A dinâmica de uma sociedade "[...] do descartável [...]”; f) Profundas mudanças na psicologia humana, por exemplo, da supremacia da estética em detrimento a ética; $h$ ) a publicidade já não parte da idéia de informar ou promover no sentido comum, voltando-se cada vez mais para a manipulação dos desejos e gostos mediante imagens que podem ou não ter relação com o produto a ser vendido. "Se privássemos a propaganda moderna da referência direta ao dinheiro, ao sexo e ao poder, pouco restaria" (HARVEY, 1992, p.260); i) Por tudo isso, acresce que as imagens se tornaram mercadorias. Essa constatação "[...] levou Baudrillard (1995) a alegar [de forma equivocada] que as análises marxistas da produção de mercadorias está ultrapassada" (HARVEY, 1992, p.260); j) A competição no mercado da construção de imagens, por exemplo, consultorias de imagem pessoal; I) $\mathrm{O}$ papel do simulacro no pós-modernismo. Por "[...] simulacro designa-se um estado de réplica tão próximo da perfeição que a diferença entre o original e a cópia é quase impossível de ser percebida" (HARVEY, 1992, p.261); m) O capital altamente móvel.

Harvey (1992) afirma que a modernidade deve ser vista como condição histórica, intermediária entre o ser e o vir-a-ser para a compreensão do espaço-tempo. Assim, o esboço histórico que o referido autor sugere para decifrar as mudanças ocorridas ao longo do século $X X$, de modo algum deve ser identificado como novo, porque a sua gênese e desenvolvimento se funda com a 
temporolis

PEREIRA, D. V. L.; JESUS, A. R. de. O PROJETO DA MODERNIDADE

constituição da sociedade capitalista. Deste modo, o arcabouço da análise a partir do materialismo histórico traz ao cenário contemporâneo elementos centrais para desvelar a realidade em seus três tempos, passado, presente e, talvez, do futuro do mundo da vida permeado pelo capital, a exemplo da Teoria do Valor formulada por Karl Marx. Posto isto, vale ressaltar a importância do legado da metanarrativa da teoria marxista porque a mesma revela o mistério de como é possível que o valor se valorize? Que mistério é este de multiplicação de mais-valor? Perguntas estas que estão mais vivas do que nunca, cujas respostas se fundam na busca do capital por lucros aonde produz e reproduz seu ciclo sempre de valorização do valor que tem na apropriação do trabalho não pago (mais-valia) a revelação deste mistério escondido graças ao caráter fetichista da mercadoria que a economia política e a ideologia burguesa buscam dissimular tendo em vista perpetuação da ordem dominante. Assim, por mais metamorfoses que o mundo do trabalho esteja passando (desemprego, flexibilização do mercado de trabalho, derrotas sucessivas da classe trabalhadora frente ao avanço das políticas neoliberais nas últimas décadas do século XX e início do século $\mathrm{XXI}$ ) é fundamental uma análise tendo em vista os pressupostos do materialismo-histórico uma vez que possibilita um viés crítico-dialético que possa fazer frente ao movimento pósmoderno Movimento esse que tem por base de reflexão a flexibilização e a fragmentação da vida posta em seu eterno vir-aser. Na perspectiva pós-moderna não é possível nenhuma formulação consistente porque tudo e todos são impactados pela simbologia da imagem, do singular, do volátil, enfim, do efêmero.

Nesse sentido, compreendemos que esse momento vem sendo propalado pela chamada crise de paradigmas no campo das ciências humanas, em especial, na sociologia, esse contexto de efervescência considera que o estudo dos fenômenos econômicos, políticos e sociais não poderiam ser analisados na sua totalidade (o 


\section{temporalis}

PEREIRA, D. V. L.; JESUS, A. R. de. O PROJETO DA MODERNIDADE

que podemos analisar são processos micro sociais, pequenos fragmentos da sociedade) uma vez que não existiria nenhuma teoria e/ou metanarrativa para explicar fenômenos sociais percebidos numa dimensão mais ampla. Pela própria realidade posta como numa espécie de caleidoscópio mutante teria que ser vista pela mistura de diversas interpretações analíticas, portanto, o ecletismo teórico é a principal tônica. Sob outro prisma, compreendemos que este momento que nega a perspectiva sóciohistórica combina, perfeitamente, com o atual ciclo de reprodução do capital em sua expressão de capital fetiche, simbolizado pelas bolsas de valores, isto é, não tem fronteiras nem momento certo para operar, sua movimentação caracteriza-se pela flexibilização e especulação sem nenhuma vinculação com o espaço e o tempo. Tal contexto favorece a configuração de um novo redesenho do mundo em constantes transformações, as quais rebatem diretamente nas várias dimensões da vida social, como no plano político, econômico e cultural.

Em suma, quando se observa determinadas medidas adotadas para a flexibilização sob a lógica do capitalismo tardio, é possível um questionamento crítico deste fenômeno já que os problemas postos pela ordem do capital não foram resolvidos, mas ampliados em todas as suas esferas sociais. De acordo com Hobsbawm (1995) existem três feixes problemáticos: o crescente alargamento da distância do mundo rico e do mundo pobre; a ascensão do racismo e da xenofobia; e a crise ecológica.

\section{CRISE DO CAPITAL E IDEOLOGIA PÓS-MODERNA}

A probabilidade em promover sucessivas crises não é fato raro no desenvolvimento do capitalismo ao longo da história. Principalmente dada a natureza e os rumos tomados a cada crise promovida pelo capital que tem seus reflexos no contexto 


\section{tempordils}

PEREIRA, D. V. L.; JESUS, A. R. de. O PROJETO DA MODERNIDADE

globalizado que temos hoje em pleno século XXI. Mudanças profundas foram produzidas, sobretudo, ao longo do século XX e começo do século XXI. Atualmente os rumos da economia deixaram de ser obrigação dos Estados Nacionais e passaram para agendas de organismos internacionais tais como: o Fundo Monetário Internacional (FMI) e o Banco Internacional para Reconstrução e Desenvolvimento (BIRD), sem falar no domínio dos mercados financeiros e a luta dos países ricos em impor suas políticas assimétricas ao restante das nações subdesenvolvidas ou em vias de desenvolvimento tais como: Brasil, Índia, Rússia e China.

A política neoliberal e sua nefasta conseqüência social com o desmantelamento do Estado, dos sindicatos, do emprego geram profundas mudanças no tecido social e consequentemente empobrecimento de parcelas significativas da população mundial. Se por um lado temos um rápido desenvolvimento da economia a nível global e do franco desenvolvimento dos meios de transporte e comunicação; por outro lado vemos avançar a miséria e a barbárie ao redor do planeta que tem na crise ambiental a sua face mais evidente no contexto atual. Caso o capitalismo seja essa força destruidora que dissolve tudo conforme salientou Berman (1982), então que futuro a humanidade herdará tendo em vista o atual ritmo de destruição patrocinada pela sociedade burguesa? Os níveis de destruição e exploração alcançados na atual fase do capitalismo apontam para crises cada vez mais severas e destrutivas trazendo consigo a marginalização e o aprofundamento das disparidades entre ricos e pobres no mundo. O que Adorno (2003) define como sendo a barbárie capitalista poderia ser encontrada na própria destruição da civilização. A barbárie vista agora vai além de um simples retorno, pois ela estaria na própria civilização.

Observar-se, portanto que dentro desta perspectiva pautada no declínio do esclarecimento e crises profundas produzidas pelo capital 


\section{tempordils}

PEREIRA, D. V. L.; JESUS, A. R. de. O PROJETO DA MODERNIDADE

tivemos como conseqüências, por exemplo, o surgimento de ideologias de cunho racista no qual o nazismo buscou semear enquanto ideologia baseada na superioridade do povo ariano ${ }^{5}$. Retomada logo após o final da segunda guerra mundial, tais ideologias estariam de volta a partir do fim da década de 1970 com o advento das teorias pós-modernas e sua crítica incisiva a razão iluminista. Sob o símbolo desta pós-modernidade constrói-se um imaginário de modernidade que necessariamente deveria ser suprimido para dar lugar a um mundo plural, diverso, sem passado e sem futuro.

No mundo pós-moderno de estilos e padrões de vida livremente concorrentes, há ainda um severo teste de pureza que se requer seja transposto por todo aquele que solicite ser ali admitido: tem de mostrar-se capaz de ser seduzido pela infinita possibilidade e constante renovação promovida pelo mercado consumidor, de regozijar com a sorte de vestir e despir identidades, de passar a vida na caça interminável de cada vez mais intensas sensações e cada vez mais inebriante experiência. Nem todos podem passar nesta prova. Aqueles que não podem são a 'sujeira' da pureza pósmoderna (BAUMAN, 1998, p. 23).

Conforme a citação do autor o mundo pós-moderno estaria se preparando para a vida sob a condição da incerteza como algo permanente e irredutível. Concepção essa bastante difundida junto ao conjunto da sociedade nos dias atuais, porém seus efeitos são mitigados em relação à classe dominante uma vez que é justamente na classe trabalhadora que recai seus efeitos mais nefastos que se traduz na mendicância, fome e doenças frente a uma democracia burguesa

${ }^{5}$ O documentário O Triunfo da Vontade sob direção de Leni Riefenstahl rodado em 1934 para cobrir o sexto congresso do Partido Nazista na cidade de Nuremberg é um exemplo contundente da ideologia nazista referendada no mito da superioridade do povo ariano, cujas consequências foram catastróficas para a humanidade resultando na eclosão da II Guerra Mudial.

Temporalis, Brasilia (DF), ano 10, n.20, p.31-47, jul./dez. 2010. 


\section{tempordils}

PEREIRA, D. V. L.; JESUS, A. R. de. O PROJETO DA MODERNIDADE

incapaz de suprir todas as necessidades do proletariado. Tanto o mercado financeiro como a classe dominante não poderia ou não devem correr o risco de vivenciar essa incerteza irredutível amplamente divulgada pelo pensamento pós-moderno.

A rigor a nova formulação teórica prega também não apenas a crise do pensamento burguês e de sua decadência econômica, mas a crise do próprio ato de refletir tendo como êxito o esclarecimento. Essa corrente teórica atribui à razão grande parte das tragédias contemporâneas, e não à reprodução do capital. Logo após a crise de 1929 o capital adota uma forma mais expansiva que resultou, dentre outras, na passagem de um imperialismo multifacetado, intervencionista para um sistema de dominação global sob hegemonia norte-americana tornando-se bastante integrador do ponto de vista econômico (CHESNAIS, 2007).

Portanto, a questão central posta pela lógica de produção e circulação capitalista, qual seja, o impasse na sobrevivência da humanidade, subordinada às leis da mercadoria e à destruição em massas de forças produtivas que se sucede a cada crise econômica, parece ofuscar-se em função de fatos de ordem conjuntural. No momento em que se discutem a face econômica da crise preocupam-se mais em descobrir os culpados pela irracionalidade do capitalismo em constantes retrocessos resultando sempre em crise e depressão. As questões econômicas se voltam sempre para a busca de saídas pontuais para o ciclo de crise, permanecendo a perspectiva de continuidade do modo de produção burguês.

\section{CONSIDERAÇÕES FINAIS}

Apresentamos aqui os pontos principais do projeto da modernidade em oposição ao discurso pós-moderno e sua perspectiva de por abaixo os pressupostos da razão. Neste sentido 


\section{tempordils}

PEREIRA, D. V. L.; JESUS, A. R. de. O PROJETO DA MODERNIDADE

foi possível expor as características fundamentais de ambos os discursos revelando assim as possíveis contradições vivenciadas pela sociedade burguesa ao longo da história do desenvolvimento do capitalismo até os dias atuais. Dito desta forma é ponto positivo o debate sobre os efeitos da modernização no estabelecimento de novas estruturas sociais sob o domínio do capital. O esforço é válido tendo em vista as profundas contradições no qual perpassa a sociedade contemporânea nos seus mais variados aspectos: econômico, político, social e cultural.

Caso seja verdadeiro que na atual fase da exploração capitalista o grau de complexidade da sociedade impede uma abordagem macroestrutural dos grandes dilemas da humanidade (desemprego, fome, miséria, pobreza, genocídio, crise ambiental, etc.); tão pouco esclarecedoras são as análises pautadas em discursos particularizados de determinados fenômenos sociais como desejam alguns teóricos da pós-modernidade.

Em resumo podemos compreender a modernidade enquanto um processo histórico dialético que possibilita uma compreensão mais pertinente sobre as sucessivas crises pelo qual o capitalismo sempre se depara, bem como, as conseqüências advindas deste processo de reestruturação do capital ao longo dos últimos 30 anos.

Portanto, a discussão teórica sobre os reflexos da modernidade na sociedade contemporânea, desenvolvida neste trabalho, se constituiu no elemento principal pelo qual buscamos discorrer sobre as mudanças produzidas pelo capital, sobretudo, no que diz respeito ao seu poder de transformação e destruição tanto da natureza como da sociedade. 


\section{temporolis}

PEREIRA, D. V. L.; JESUS, A. R. de. O PROJETO DA MODERNIDADE

\section{REFERÊNCIAS}

ADORNO, T. Educação e emancipação. Rio de Janeiro: Paz e Terra, 2003.

BAUDRILLARD, J. Para uma crítica da economia política do signo. Rio Janeiro: Elfos; Lisboa: Edições 70, 1995. (Coleção Ciência e Sociedade, 2).

BAUMAN, Z. O mal-estar da pós-modernidade. Rio de Janeiro: Jorge Zahar, 1998.

BERMAN, M. Tudo que é sólido desmancha no ar: a aventura da modernidade. São Paulo: Companhia das Letras, 1982.

CHESNAIS, F. Da noção de imperialismo e da análise de Marx do capitalismo: pré/visões da crise. In: NÓvOA, J. (Org.). 0 Incontornável Marx. Salvador: EDUFBA; São Paulo: UNESP, 2007.

HABERMAS, J. O discurso filosófico da modernidade. São Paulo: Martins Fontes, 2002.

. Técnica e ciência como "ideologia". In: BENJAMIN, W. et al. Textos escolhidos. São Paulo: Abril Cultural, 1975. (Coleção Os Pensadores).

HARVEY, D. Condição pós-moderna. São Paulo: Loyola, 1992.

HEGEL, G. W. F. A fenomenologia do espírito. Petrópolis: Vozes, 2008.

HOBSBAWM, E. J. A Era dos extremos: o breve século XX. São Paulo: Companhia das Letras, 1995. 


\section{temporalis}

PEREIRA, D. V. L.; JESUS, A. R. de. O PROJETO DA MODERNIDADE

MARX, K. A ideologia alemã. São Paulo: Editora Hucitec, 1999.

- Manifesto do Partido Comunista. São Paulo: Martin Claret, 2001. 
